\title{
Optimum Design of Novel UWB Multilayer Microstrip Hairpin Filters with Harmonic Suppression and Impedance Matching
}

\author{
Homayoon Oraizi and Nima Azadi-Tinat \\ Department of Electrical Engineering, Iran University of Science and Technology, Narmak, Tehran 1614813114, Iran \\ Correspondence should be addressed to Homayoon Oraizi, h_oraizi@iust.ac.ir \\ Received 13 May 2012; Accepted 3 August 2012 \\ Academic Editor: Tat Yeo
}

Copyright (C) 2012 H. Oraizi and N. Azadi-Tinat. This is an open access article distributed under the Creative Commons Attribution License, which permits unrestricted use, distribution, and reproduction in any medium, provided the original work is properly cited.

Optimum design of a novel ultra-wideband multilayer microstrip hairpin filter is presented, providing for harmonic suppression and impedance matching between source and load impedances. The theory of $\mathrm{N}$-coupled transmission lines is employed to obtain an equivalent circuit for development of a design procedure based on the method of least squares. A prototype model of proposed two-layer filter of order 5 is fabricated for 3.1-10.6 GHz. The dimensions of designed filter are $23 \mathrm{~mm} \times 7 \mathrm{~mm}$. The insertion loss in the passband varies from $0.3 \mathrm{~dB}$ to $3 \mathrm{~dB}$ (in the worst case at the edge of passband) and in the stopband is about $30 \mathrm{~dB}$ up to $20 \mathrm{GHz}$. Its group delay in the UWB region is about $0.5 \mathrm{~ns}$. Close agreement among the filter frequency responses as obtained by the proposed method, full-wave computer simulation softwares, and measurement data verify the effectiveness of the proposed filter structure and design methods.

\section{Introduction}

In the year 2002, the USA Federal Communications Commission (FCC) allocated the frequency band $3.1-10.6 \mathrm{GHz}$ to the ultra wideband (UWB) commercial applications [1]. In recent years, UWB technology has been applied to various communication and radar systems. Accordingly, considerable efforts have been spent in the investigation for the development and realization of various UWB configurations and structures [2-10].

The microstrip hairpin filters have been extensively used in microwave circuits due to their low weight, simple configuration, and ease of design and implementation [11-13]. However, they are not suitable for UWB single layer planar applications, since the coupled strip edges of resonators need to be very close, which may not be realizable by available photolithography technology. On the other hand, if the same hairpin filter is designed on a two-layer configuration, then the required coupling is obtained conveniently, since the edge coupling is replaced by broad side coupling through the substrate with fixed height.

Since the hairpin filter structure uses coupled lines, its stopband exhibits extraneous spurious response. In order to remove such responses, we place open-ended stubs between the coupled strips to considerably reduce the filter response in the stopband.

In this paper, we introduce a two-layer hairpin filter configuration for UWB applications, which removes the spurious response in its stopband through the connection of open-ended stub. An equivalent circuit is derived for it, which is used to develop a design procedure based on the method of least squares, which determines the optimum filter geometrical dimensions. A two-layer hairpin filter is designed and fabricated. The measurement data and fullwave simulation results verify the performance of proposed hairpin filter configuration and optimum design method.

\section{Design Procedure}

An N-section two layer microstrip hairpin filter configuration is depicted in Figure 1, which is composed of parallel coupled line sections joined by strips having open-ended stubs. The input and output ports are connected to the Ushaped strips at the two ends of the filter. Its equivalent circuit is shown in Figure 2, which is composed of straight 


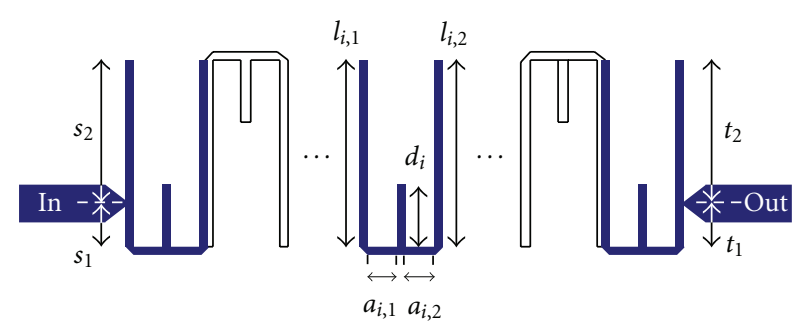

FIGURE 1: Schematic diagram of proposed multilayer microstrip hairpin filter.

strips, bends, T-junctions, and coupled lines. The transmission matrices of bends and $\mathrm{T}$-junctions are obtained in Appendix A. The impedance matrix of the four port network of a pair of coupled lines $[Z]_{4 \times 4}$ is first obtained [14]. The impedance matrix of the two port network $[Z]_{2 \times 2}$ is then determined by open circuiting its two ports. Finally, the transmission matrix of the two port coupled-lines $\left[T_{C}\right]_{2 \times 2}$ is derived.

Consequently, the transmission matrices of the filter network are composed of $\left[T_{s 1}\right]$ for the line section at the input, $\left[T_{m}\right]_{i}$ for the section joining the two consecutive coupled lines, $\left[T_{c}\right]_{i}$ for the coupled lines and $\left[T_{t 1}\right]$ for the line section at the output. The transmission matrix of this part of the multisection two-layer hairpin filter is then

$$
\left[T^{\prime}\right]=\left[T_{s 1}\right]\left(\prod_{i=1}^{N-1}\left[T_{m}\right]_{i}\left[T_{C}\right]_{i}\right)\left[T_{m}\right]_{N}\left[T_{t 1}\right] .
$$

We now convert it to its equivalent impedance matrix as

$$
\left[\begin{array}{l}
V_{S} \\
V_{L}
\end{array}\right]=\left[Z^{\prime}\right]\left[\begin{array}{c}
I_{1} \\
I_{1}^{\prime}
\end{array}\right]
$$

Referring to Figure 2, we observe the following relations for the currents at the input and output ports:

$$
\begin{aligned}
& I_{S}=I_{B}+I_{1}=j Y_{s 2} \tan \left(\beta_{s 2} s_{2}\right) V_{S}+I_{1}, \\
& I_{L}=I_{B}^{\prime}+I_{1}^{\prime}=j Y_{t 2} \tan \left(\beta_{t 2} t_{2}\right) V_{L}+I_{1},
\end{aligned}
$$

which may be used in (2) to obtain the whole impedance matrix of the filter as

$$
\left[\begin{array}{c}
V_{S} \\
V_{L}
\end{array}\right]=\left[Z_{i o}\right]\left[\begin{array}{c}
I_{S} \\
I_{L}
\end{array}\right]
$$

where

$$
\begin{aligned}
& {\left[Z_{i o}\right]=} \\
& \quad\left([U]-\left[Z^{\prime}\right]\left[\begin{array}{cc}
j Y_{s 2} \tan \left(\beta_{s 2} s_{2}\right) & 0 \\
0 & j Y_{t 2} \tan \left(\beta_{t 2} t_{2}\right)
\end{array}\right]\right)^{-1}\left[Z^{\prime}\right] .
\end{aligned}
$$

Finally, the overall transmission matrix of the filter may be obtained to determine its scattering parameters as the insertion loss $\left(s_{21}\right)$ and return loss $\left(s_{11}\right)$

$$
\begin{aligned}
s_{21, k} & =\frac{2}{A_{k}+B_{k} Y_{l, k}+C Z_{s, k}+D_{k} Z_{s, k} Y_{l, k}}, \\
s_{11, k} & =\frac{A_{k}-B_{k} Y_{l, k}+C Z_{s, k}-D_{k} Z_{s, k} Y_{l, k}}{A_{k}+B_{k} Y_{l, k}+C Z_{s, k}+D_{k} Z_{s, k} Y_{l, k}} .
\end{aligned}
$$

They may be expressed

$$
\begin{aligned}
& \mathrm{IL}_{k}=-20 \log \left(\left|s_{21, k}\right|\right), \\
& \mathrm{RL}_{k}=-20 \log \left(\left|s_{11, k}\right|\right),
\end{aligned}
$$

where the subscript $k$ indicates the $k^{\text {th }}$ frequency in the specified frequency bandwidth and $Z_{S}$ and $Y_{L}$ are the source impedance and load admittance, respectively.

We now specify the desired frequency response of the filter as shown in Figure 3, which is composed of the lower stop and transition bands, passband, and upper transition and stop bands. The frequency limits of these bands and their levels are indicated in Figure 3.

We then construct an error function as

$$
\begin{aligned}
e=w t_{1} & \sum_{k=1}^{n_{\mathrm{SL}}}\left(\mathrm{IL}_{k}-\mathrm{ILSB}_{k}\right)^{2}+w t_{2} \sum_{k=n_{\mathrm{SL}}}^{n_{\mathrm{PL}}}\left(\mathrm{IL}_{k}-g_{\mathrm{TL}}\left(f_{k}\right)\right)^{2} \\
& +w t_{3} \sum_{k=n_{\mathrm{PL}}}^{n_{\mathrm{PU}}}\left(\mathrm{IL}_{k}-\mathrm{ILPB}_{k}\right)^{2}+w t_{4} \sum_{k=n_{\mathrm{PU}}}^{n_{\mathrm{SU}}}\left(\mathrm{IL}_{k}-g_{\mathrm{TU}}\left(f_{k}\right)\right)^{2} \\
& +w t_{5} \sum_{k=n_{\mathrm{SU}}}^{K}\left(\mathrm{IL}_{k}-\mathrm{ILSB}_{k}\right)^{2}
\end{aligned}
$$

where the specified frequency band is divided into $K$ discrete frequencies, ILSB and ILPB are the desired insertion losses in the stop and pass bands, and $g_{\mathrm{TL}}\left(f_{k}\right)$ and $g_{\mathrm{TU}}\left(f_{k}\right)$ are the linear functions in the lower and upper transition bands, respectively which join the stop and pass bands, and $w t_{i}$ are the weighting functions which enhance the effect of different bands relative to each other.

The selection of the values of weighting functions $\left(w t_{i}\right)$ may be made on the basis of some experience and experimentation with the algorithm. Their relative values may place some emphasis on the various sections of the response. For example, if the satisfaction of the response in the passband is of more interest, then the value of weighting function of its term in the error function is made relatively larger. Furthermore, the values of the terms in error function may be considered at various iterations of the algorithm and the values of weighting function may be adjusted accordingly.

The error function depends on the geometrical dimensions of the filter (such as the widths and length of strips and gaps between strips) as shown in Figure 1, which may be determined by its minimization carried out by Fmincon () function in MATLAB [15]. 


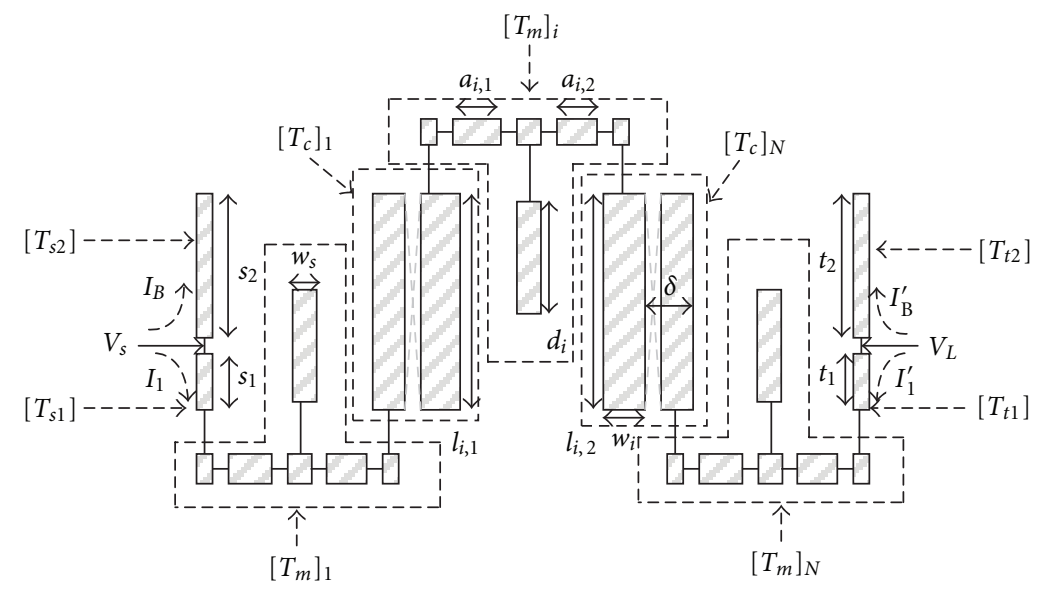

FIgURE 2: The equivalent circuit of hairpin filter shown in Figure 1.

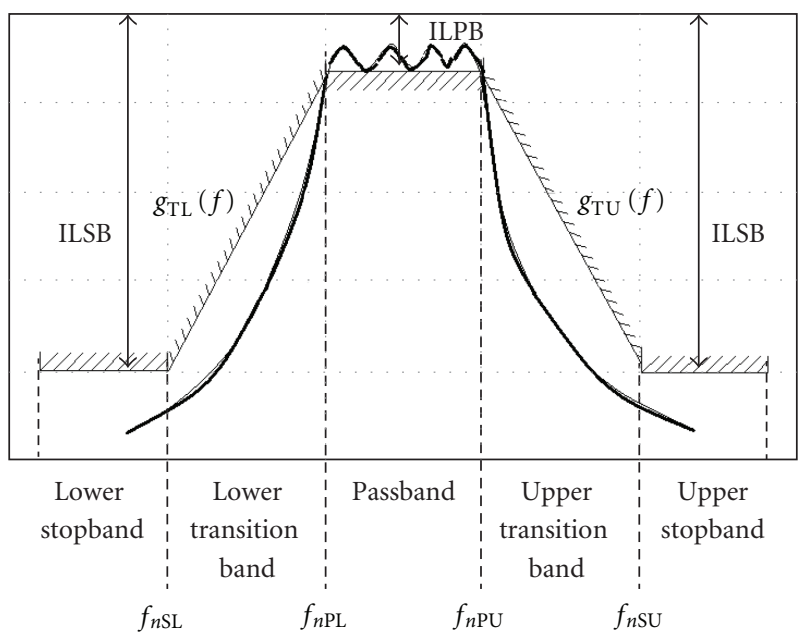

FiguRE 3: Specified frequency response of the bandpass filter.

The initial values of the dimensions of hairpin filter are selected with reference to Figure 1, namely,

$$
L_{i}=a_{i, 1}+l_{i, 1}=\frac{\lambda_{g}}{4}=\frac{\lambda_{0}}{4 \sqrt{\varepsilon_{\mathrm{eff}}}},
$$

where $\varepsilon_{\text {eff }}$ is the effective dielectric constant of the substrate. Furthermore, the best ratio of $l_{i, 1}$ to $a_{i, 1}$ is obtained to be about 2.5. The width of stripline sections are all set equal to $1 \mathrm{~mm}$, which give a characteristic impedance of about $62 \Omega$ (for the effective dielectric constant of the forthcoming design example consisting of two different substrate layers). The widths could be made variable too, but the CPU time for the filter design would have increased considerably. The value of the stub lengths (di) is selected to produce a transmission zero at about $12 \mathrm{GHz}$ (see Appendix B). As the optimization process proceeds, the transmission zeros will move in such a way as to suppress the harmonic responses. The connection point of the input and output lines to the filter are selected in the ratio of [13] as follows:

$$
\frac{s 1}{s 2}=\frac{t 1}{t 2}=0.5
$$

The minimization procedure for the error function may be conducted by the combination of genetic algorithm (GA) and conjugate gradient method (CG) in MATLAB. GA is first started which is a global minimum seeking algorithm and may not need initial values, but it is CPU time consuming. Observe that GA selects the lowest minimum point among several minimum points. (We employ the following default options of MATLAB GA: mutationgaussian and crossover $=0.8$. We impose some constraints on the parameter values, namely, the lower constraint values (Lb) are zero and the upper constraint values (Ub) are three times the selected initial values, as described above). It is then aborted and CG takes over, which is a local minimum seeking algorithm needing initial values, but it is relatively fast. CG proceeds until some specified criterion is satisfied, such as the value or slopes of error function or a specified maximum number of iterations of the algorithm. Observe that it is not feasible to locate the absolute minimum of the complicated error function. Such a procedure is very costly and time consuming and its benefits for obtaining the most optimum performance of filter is doubtful.

The strongest couplings in the multilayer structure for the best passband response are achieved for the case where the adjacent strips are exactly above each other, without any relative displacement.

\section{Design Examples}

Two examples of filter design are provided. The first example is for different source and load impedances, namely, $45 \Omega$ and $100 \Omega$, respectively. The second example is for the same input and output impedances, namely, $50 \Omega$. For both examples, the lower substrate is RO4003 (with $\varepsilon_{r}=3.55$, height $h=0.508 \mathrm{~mm}$ and $\tan \delta=0.0027)$. The upper substrate is 
TABLe 1: Filter design specifications for Examples 1 and 2.

\begin{tabular}{|c|c|c|c|c|c|c|c|c|c|c|c|c|c|}
\hline$K$ & $n_{s l}$ & $n_{p l}$ & $n_{p u}$ & $n_{s u}$ & $f_{l}$ & $f_{s l}$ & $f_{p l}$ & $f_{p u}$ & $f_{s u}$ & $f_{u}$ & $\mathrm{ILSB}_{l} \quad \mathrm{ILPB}_{u}$ & $\operatorname{ILSB}_{u}($ Example 1$)$ & $\operatorname{ILSB}_{u}($ Example 2$)$ \\
\hline 140 & 10 & 20 & 120 & 140 & $1 \mathrm{GHz}$ & $2 \mathrm{GHz}$ & $3.1 \mathrm{GHz}$ & $10.6 \mathrm{GHz}$ & $12 \mathrm{GHz}$ & $20 \mathrm{GHz}$ & $30 \mathrm{~dB} \quad 0.1 \mathrm{~dB}$ & $40 \mathrm{~dB}$ & $30 \mathrm{~dB}$ \\
\hline
\end{tabular}

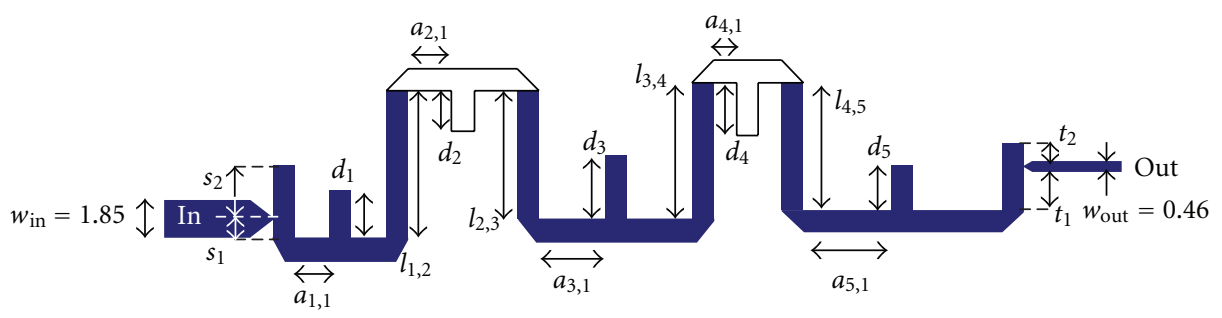

Figure 4: Schematic of the proposed multilayered microstrip hairpin filter.

RO5880 (with $\varepsilon_{r}=2.2$, height $h=0.127 \mathrm{~mm}$ and $\tan \delta=$ $0.0009)$.

The filter design specifications indicated in the filter frequency response in Figure 3 are given in Table 1 for both examples.

Example 1. Consider the layout of the UWB two-layer hairpin filter shown in Figure 4, where the geometrical dimensions are indicated. The initial values of the filter dimensions are given in Table 2 . The source and load impedances are $Z_{S}=45 \Omega$ and $Z_{L}=100 \Omega$. The frequency responses of the filter as insertion loss $\left(s_{21}\right)$ and return loss $\left(s_{11}\right)$ obtained by our proposed design procedure, HFSS and IE3D full-wave simulation softwares $[16,17]$ are shown in Figure 5 for comparison. Furthermore, the group delay of the designed filter is obtained by HFSS and IE3D softwares and drawn in Figure 6. Observe that group delay is quite constant in the specified bandwidth $3.1-10.6 \mathrm{GHz}$.

Example 2. Consider the layout of the UWB two layer hairpin filter shown in Figure 7, where the geometrical dimensions are indicated. The initial values of the filter dimensions are given in Table 3 . The source and load impedance are $Z_{S}=Z_{L}=50 \Omega$. A photograph of the fabricated hairpin filter is shown in Figure 8. The frequency response of the filter as insertion loss $\left(s_{21}\right)$ and return loss $\left(s_{11}\right)$ obtained by our proposed design procedure, HFSS and IE3D full-wave simulation softwares [16, 17] and measurement data are shown in Figure 9 for comparison. Furthermore, the group delay of the designed filter is obtained by the HFSS and IE3D softwares and drawn in Figure 10. Observe that group delay is quite constant in the specified bandwidth $3.1-10.6 \mathrm{GHz}$. The simulation results and measurement data do not exactly coincide, especially at higher frequencies due to the imperfect available fabrication technology. Furthermore, the heat generated during the process of soldering connectors, gives rise to air bubbles between the two layers, which eventually increases losses.

\section{Conclusion}

A multilayer microstrip hairpin bandpass filter with the capability of effective suppression of spurious response is
TABLE 2: Parameters of designed proposed multilayered microstrip hairpin filter (Example 1).

\begin{tabular}{lr}
\hline $\begin{array}{l}N=5, \mathrm{ILSB}=40 \mathrm{~dB}, \mathrm{ILPB}=0.1 \mathrm{~dB}, \mathrm{UWB}, Z_{s}=45 \Omega, \\
\quad Z_{l}=100 \Omega, w_{i}=1 \mathrm{~mm}, a_{i, 1}=a_{i, 2} \text { and } l_{i, 2}=l_{i+1,1} \\
\text { Initial value }\end{array}$ \\
\hline$a_{1,1}=2 \mathrm{~mm}$ & $a_{1,1}=1.55 \mathrm{~mm}$ \\
$a_{2,1}=2 \mathrm{~mm}$ & $a_{2,1}=2.00 \mathrm{~mm}$ \\
$a_{3,1}=2 \mathrm{~mm}$ & $a_{3,1}=3.00 \mathrm{~mm}$ \\
$a_{4,1}=2 \mathrm{~mm}$ & $a_{4,1}=1.05 \mathrm{~mm}$ \\
$a_{5,1}=2 \mathrm{~mm}$ & $a_{5,1}=4.00 \mathrm{~mm}$ \\
$d_{1}=3 \mathrm{~mm}$ & $d_{1}=2.15 \mathrm{~mm}$ \\
$d_{2}=3 \mathrm{~mm}$ & $d_{2}=1.87 \mathrm{~mm}$ \\
$d_{3}=3 \mathrm{~mm}$ & $d_{3}=2.95 \mathrm{~mm}$ \\
$d_{4}=3 \mathrm{~mm}$ & $d_{4}=2.47 \mathrm{~mm}$ \\
$d_{5}=3 \mathrm{~mm}$ & $d_{5}=2.00 \mathrm{~mm}$ \\
$s_{1}=1 \mathrm{~mm}$ & $s_{1}=0.80 \mathrm{~mm}$ \\
$s_{2}=2 \mathrm{~mm}$ & $s_{2}=2.40 \mathrm{~mm}$ \\
$t_{1}=1 \mathrm{~mm}$ & $t_{1}=1.95 \mathrm{~mm}$ \\
$t_{2}=2 \mathrm{~mm}$ & $t_{2}=1.06 \mathrm{~mm}$ \\
$l_{1,2}=5 \mathrm{~mm}$ & $l_{1,2}=6.72 \mathrm{~mm}$ \\
$l_{2,2}=5 \mathrm{~mm}$ & $l_{2,2}=5.89 \mathrm{~mm}$ \\
$l_{3,2}=5 \mathrm{~mm}$ & $l_{3,2}=6.27 \mathrm{~mm}$ \\
$l_{4,2}=5 \mathrm{~mm}$ & $l_{4,2}=5.81 \mathrm{~mm}$ \\
\hline &
\end{tabular}

presented together with an optimum design procedure based on the theory of $\mathrm{N}$-coupled transmission line and method of least squares. For the verification of the proposed hairpin filter structure and design procedure, a two-layer microstrip filter of order 5 was designed, fabricated, and tested by measurement and full-wave simulation, with favorable and supporting results. The couplings obtained among the layers and provision of open-circuited stubs inside the filter structure provide the capability of obtaining UWB response, deep stop bands, and realization of the function of impedance matching by the filter configuration. The frequency response of the proposed two-layer filter is superior to that of a twolayer filter in [8] and its size is about 20\% smaller. Example 2 designed here for a two-layer filter provides a frequency response comparable to the filter in [7]. However, Example 1 


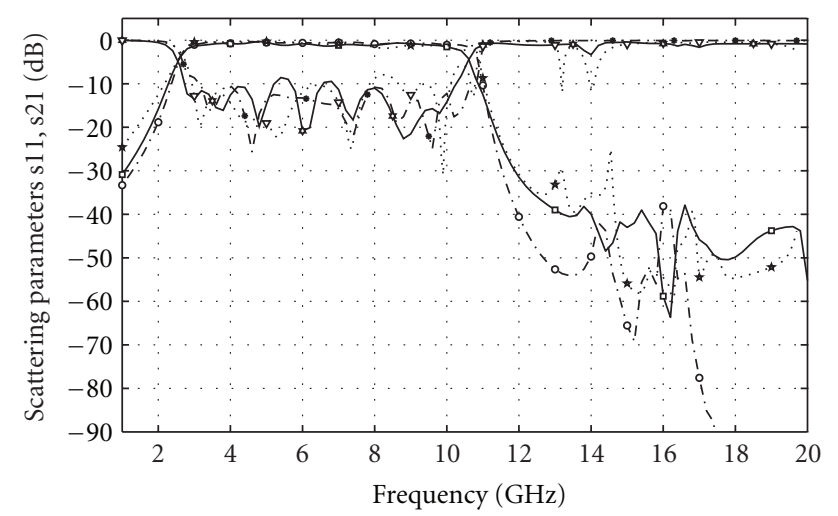

- o-s21 predicted by MATLAB s11 simulated by IE3D

* - s11 predicted by MATLAB ... s21 simulated by HFSS

$\neg \square$ s21 simulated by IE3D $\quad \cdot \nabla^{\prime} \cdot$ s 11 simulated by HFSS

Figure 5: Comparison of the frequency response of proposed multilayered microstrip hairpin filter as obtained by the simulation softwares (IE3D and HFSS) and those predicted by MATLAB (Example 1).

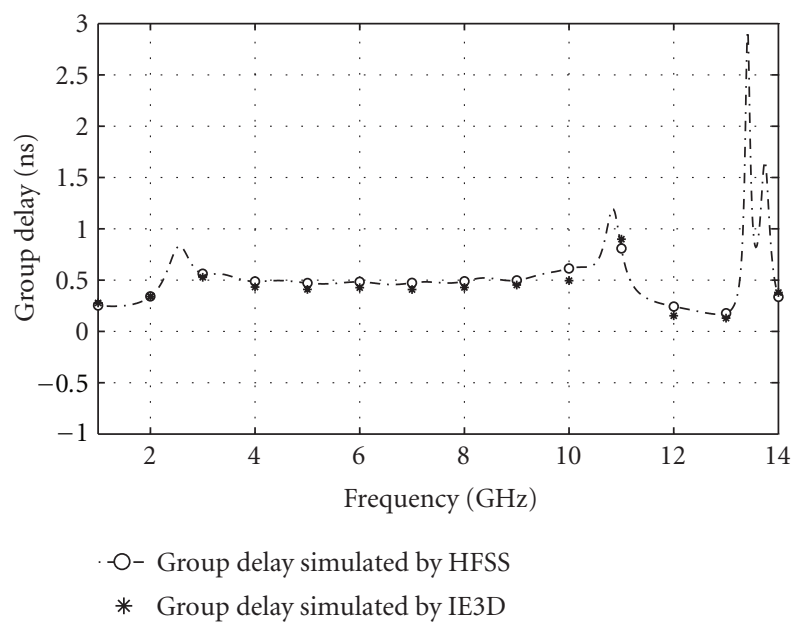

FIgURE 6: Comparison of the group delay of example 3 as obtained by the simulation softwares (HFSS and IE3D) (Example 1).

designed here for different source and load impedance has superior characteristics, particularly in the stopband.

\section{Appendices}

\section{A. Transmission Matrices of Bends and T-Junctions}

The schematic diagram of two mitered bends at the two ends of the straight arm of a T-junction and its equivalent circuit is shown in Figure 11. The equivalent circuit of a $90^{\circ}$ microstrip corner having line width $w_{1}$ and $w_{2}$ on its two sides is approximately taken as two line sections having lengths equal to $0.35 w_{1}$ and $0.35 w_{2}$, respectively $[14,18,19]$.

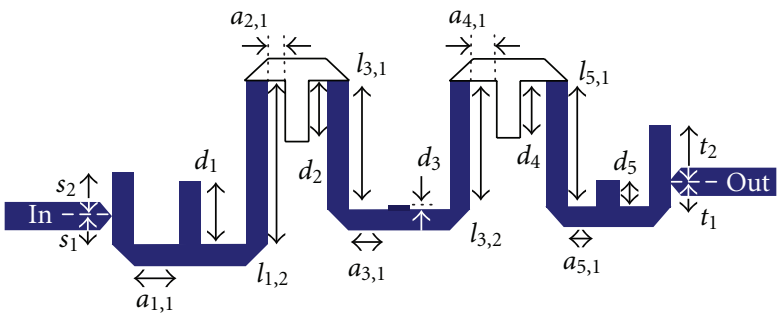

FIGURE 7: Schematic of the proposed multilayered microstrip hairpin filter.

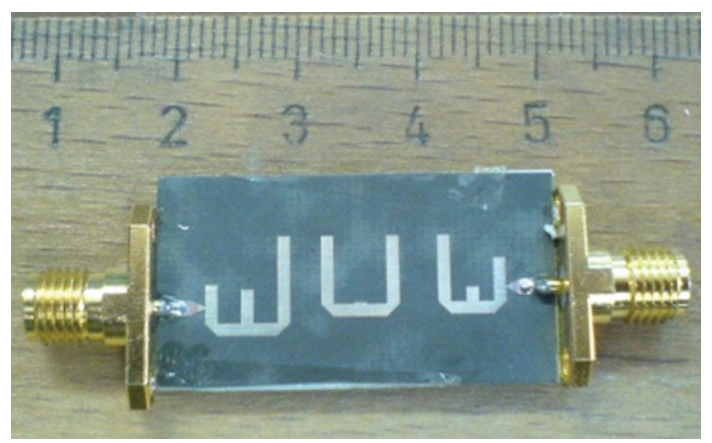

FIGURE 8: The photograph of the fabricated filter.

TABLE 3: Parameters of designed proposed multilayered microstrip hairpin filter (Example 2).

\begin{tabular}{|c|c|}
\hline \multicolumn{2}{|c|}{$\begin{array}{c}N=5, \mathrm{ILSB}=30 \mathrm{~dB}, \mathrm{ILPB}=0.1 \mathrm{~dB}, \mathrm{UWB}, Z_{s}=50 \Omega, \\
Z_{l}=50 \Omega, w t_{i}=1, a_{i, 1}=a_{i, 2} \text { and } l_{i, 2}=l_{i+1,1}\end{array}$} \\
\hline Initial value & Design and optimization \\
\hline$a_{1,1}=2 \mathrm{~mm}$ & $a_{1,1}=1.83 \mathrm{~mm}$ \\
\hline$a_{2,1}=2 \mathrm{~mm}$ & $a_{2,1}=0.72 \mathrm{~mm}$ \\
\hline$a_{3,1}=2 \mathrm{~mm}$ & $a_{3,1}=0.60 \mathrm{~mm}$ \\
\hline$a_{4,1}=2 \mathrm{~mm}$ & $a_{4,1}=1.00 \mathrm{~mm}$ \\
\hline$a_{5,1}=2 \mathrm{~mm}$ & $a_{5,1}=1.18 \mathrm{~mm}$ \\
\hline$d_{1}=3 \mathrm{~mm}$ & $d_{1}=2.64 \mathrm{~mm}$ \\
\hline$d_{2}=3 \mathrm{~mm}$ & $d_{2}=2.53 \mathrm{~mm}$ \\
\hline$d_{3}=3 \mathrm{~mm}$ & $d_{3}=0.10 \mathrm{~mm}$ \\
\hline$d_{4}=3 \mathrm{~mm}$ & $d_{4}=2.36 \mathrm{~mm}$ \\
\hline$d_{5}=3 \mathrm{~mm}$ & $d_{5}=1.11 \mathrm{~mm}$ \\
\hline$s_{1}=1 \mathrm{~mm}$ & $s_{1}=1.18 \mathrm{~mm}$ \\
\hline$s_{2}=2 \mathrm{~mm}$ & $s_{2}=1.86 \mathrm{~mm}$ \\
\hline$t_{1}=1 \mathrm{~mm}$ & $t_{1}=1.06 \mathrm{~mm}$ \\
\hline$t_{2}=2 \mathrm{~mm}$ & $t_{2}=2.38 \mathrm{~mm}$ \\
\hline$l_{1,2}=5 \mathrm{~mm}$ & $l_{1,2}=6.87 \mathrm{~mm}$ \\
\hline$l_{2,2}=5 \mathrm{~mm}$ & $l_{2,2}=5.43 \mathrm{~mm}$ \\
\hline$l_{3,2}=5 \mathrm{~mm}$ & $l_{3,2}=5.44 \mathrm{~mm}$ \\
\hline$l_{4,2}=5 \mathrm{~mm}$ & $l_{4,2}=5.31 \mathrm{~mm}$ \\
\hline$w_{i}=1 \mathrm{~mm}$ & $w_{i}=1 \mathrm{~mm}$ \\
\hline
\end{tabular}




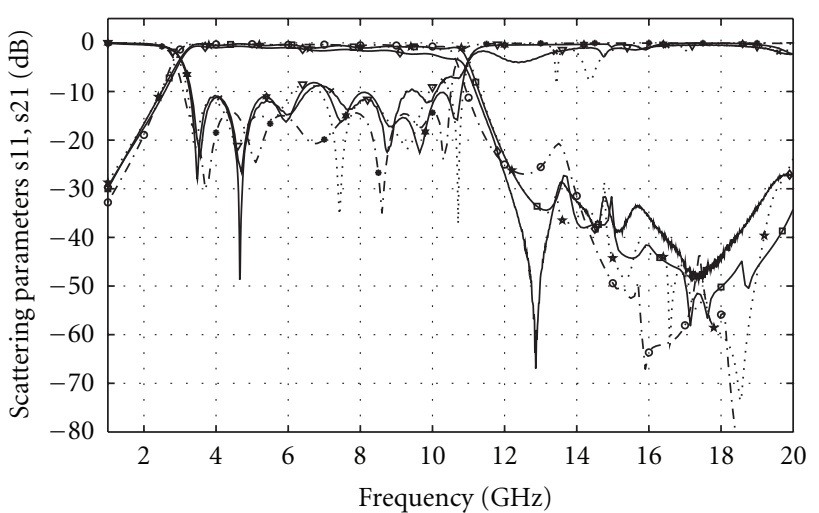

.๑- $\mathrm{s} 21$ predicted by MATLAB ...

** s11 predicted by MATLAB $\quad \cdot \nabla \cdot$. s 11 simulated by HFSS

$\square$ s21 simulated by IE3D $\diamond$ s21 measured

$\rightarrow$ s11 simulated by IE3D $\quad \leftarrow$ s11 measured

FIGURE 9: Comparison of the frequency response of proposed multilayered microstrip hairpin filter as obtained by the simulation softwares (IE3D and HFSS) and measurement data and those predicted by MATLAB (Example 2).

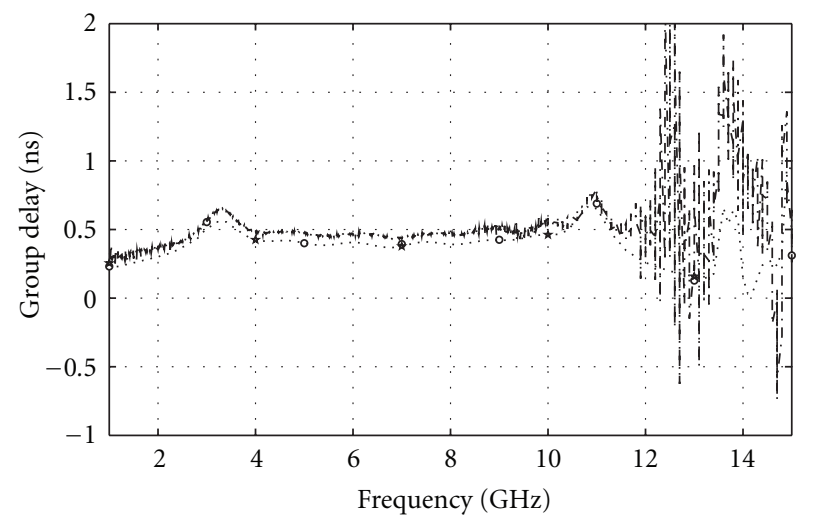

Group delay simulated by HFSS

. Group delay simulated by IE3D

-.- Group delay measured

Figure 10: Comparison of the group delay of example 3 as obtained by the simulation softwares (IE3D and HFSS) and measurement data (Example 2).

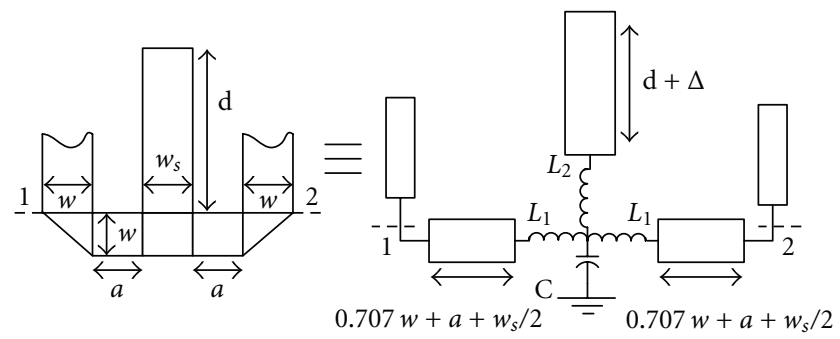

FIgURE 11: Schematic diagram and equivalent circuit of a Tjunction with two bends.

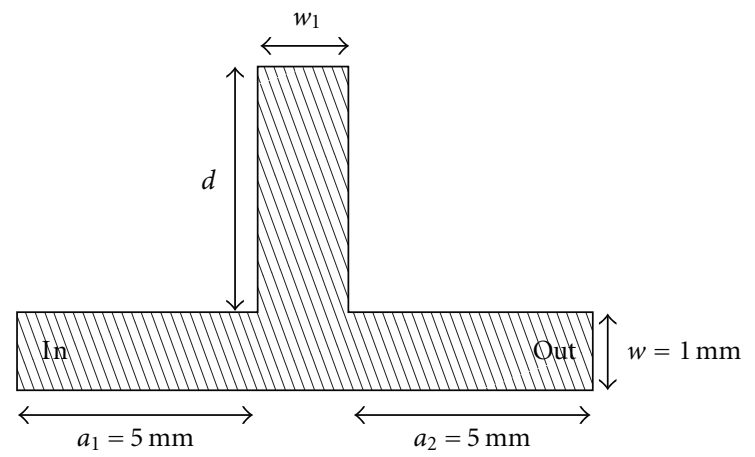

FIGURE 12: The performance of a microstrip T-junction to produce a transmission zeros.

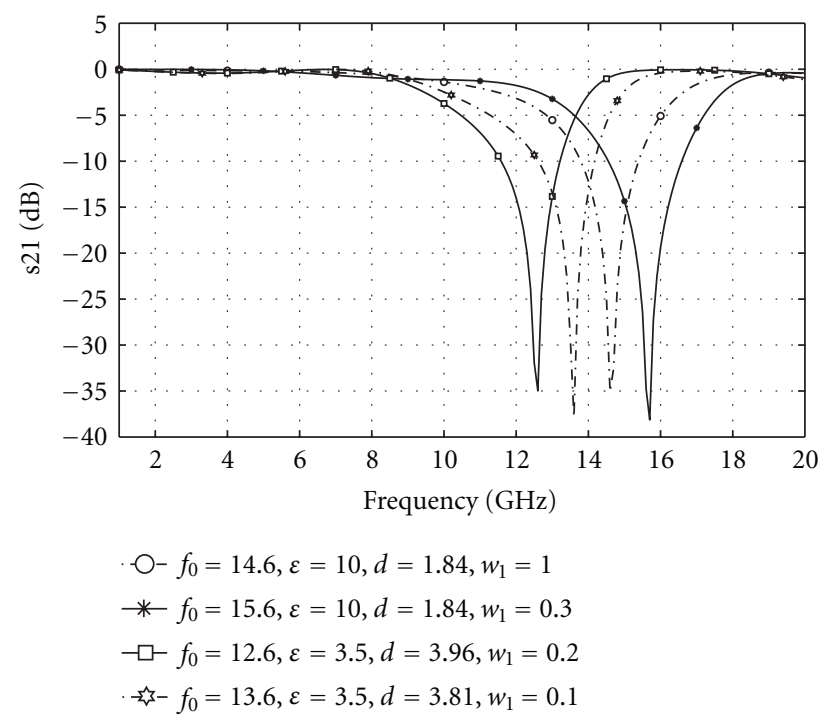

Figure 13: The transmission coefficient frequency response of the T-junction in (Figure 12) producing transmission zeros at several frequencies.

The transmission matrix between points 1 and 2 in Figure 11 may be written as

$$
\begin{aligned}
{\left[T_{m}\right]=} & {\left[\begin{array}{cc}
\cos \left(\beta l^{\prime}\right) & j Z_{0} \sin \left(\beta l^{\prime}\right) \\
j Y_{0} \sin \left(\beta l^{\prime}\right) & \cos \left(\beta l^{\prime}\right)
\end{array}\right]\left[\begin{array}{cc}
1 & j \omega L_{1} \\
0 & 1
\end{array}\right] } \\
& \times\left[\begin{array}{cc}
1 & j \omega c\left(\omega L_{2}-Z_{s} \cot \left(\beta_{s} l_{s}\right)+1\right. \\
\omega L_{2}-Z_{s} \cot \left(\beta_{s} l_{s}\right) & 0
\end{array}\right] \\
& \times\left[\begin{array}{cc}
1 & j \omega L_{1} \\
0 & 1
\end{array}\right]\left[\begin{array}{cc}
\cos \left(\beta l^{\prime}\right) & j Z_{0} \sin \left(\beta l^{\prime}\right) \\
j Y_{0} \sin \left(\beta l^{\prime}\right) & \cos \left(\beta l^{\prime}\right)
\end{array}\right],
\end{aligned}
$$

where

$$
\begin{gathered}
l^{\prime}=\frac{0.7 w+a+w_{2}}{2}, \\
l_{s}=d+\Delta .
\end{gathered}
$$

Observe that the effect of open circuit of the line section in Figure 11 is included by a line of length $\Delta$. 


\section{B. Realization of Transmission Zeros by Open Stubs}

Consider the T-junction in Figure 12, composed of a microstrip line section, where an open circuited stub is connected to its midpoint. Its transmission matrix is given in (A.1). The insertion loss $S_{21, k}$ (and equivalently $\mathrm{IL}_{k}$ ) is then computed by (6). We may now construct the error function in (10). However, in this case we should select the design specifications in reverse, namely, ILSB $=0 \mathrm{~dB}$ and ILPB $=30 \mathrm{~dB}$. The transition bands denoted by $g_{\mathrm{TL}}$ and $g_{\mathrm{TU}}$ are taken as sharp linear functions. Observe that this frequency response is inverse of the curve in Figure 3, as a bandstop filter. The error is a function of $d, a_{1}=a_{2}=$ $l^{\prime}$ and $w_{1}$. Then for a specified notch frequency, the error function is minimized to determine the dimensions of the Tjunction. The frequency response of the notch filter for center frequencies $f=12.6,13.6,14.6$, and $15.6 \mathrm{GHz}$ are drawn in Figure 13. The corresponding values of dimensions $d$ and $w_{1}$ and also selected values of $\varepsilon_{r}$ are given in Figure 13. Observe that the value of " $a$ " has negligible effect on the transmission zero at the notch frequency.

\section{References}

[1] Federal Communications Commission, Revision of Part 15 of the Commission's Rules Regarding Ultra-Wideband Transmission Systems, First Report and Order, FCC 02.V48, April 2002.

[2] L. Zhu, S. Sun, and W. Menzel, "Ultra-wideband (UWB) bandpass filters using multiple-mode resonator," IEEE Microwave and Wireless Components Letters, vol. 15, no. 11, pp. 796-798, 2005.

[3] J. S. Hong and H. Shaman, "An optimum ultra-wideband microstrip filter," Microwave and Optical Technology Letters, vol. 47, no. 3, pp. 230-233, 2005.

[4] W. T. Wong, Y. S. Lin, C. H. Wang, and C. H. Chen, "Highly selective microstrip bandpass filters for ultra-wideband (UWB) applications," in Proceedings of Asia-Pacific Microwave Conference (APMC '05), vol. 5, pp. 1-4, December 2005.

[5] S. W. Wong and L. Zhu, "EBG-embedded multiple-mode resonator for UWB bandpass filter with improved upperstopband performance," IEEE Microwave and Wireless Components Letters, vol. 17, no. 6, pp. 421-423, 2007.

[6] Z. C. Hao and J. S. Hong, "Ultrawideband filter technologies," IEEE Microwave Magazine, vol. 11, no. 4, pp. 56-68, 2010.

[7] Z. C. Hao and J. S. Hong, "Ultra-wideband bandpass filter using multilayer liquid-crystal-polymer technology," IEEE Transactions on Microwave Theory and Techniques, vol. 56, no. 9, pp. 2095-2100, 2008.

[8] Z. C. Hao and J. S. Hong, "Ultra wideband bandpass filter using embedded stepped impedance resonators on multilayer liquid crystal polymer substrate," IEEE Microwave and Wireless Components Letters, vol. 18, no. 9, pp. 581-583, 2008.

[9] Z. C. Hao and J. S. Hong, "Quasi-elliptic UWB bandpass filter using multilayer liquid crystal polymer technology," IEEE Microwave and Wireless Components Letters, vol. 20, no. 4, pp. 202-204, 2010.

[10] H. Kumar and M. Upadhayay, "Design of UWB Filter with WLAN Notch," Hindawi International Journal of Antennas and Propagation, vol. 2012, Article ID 971097, 4 pages, 2012.
[11] G. L. Matthaei, L. Young, and E. M. T. Jones, Microwave Filters, Impedance Matching Networks and Coupling Structures, Artech House, Norwood, Mass, USA, 1980.

[12] I. Hunter, Theory and Design of Microwave Filters, IEE Press, London, UK, 2001.

[13] J. S. Hong and M. J. Lancaster, Microstrip Filters for RF/ Microwave Applications, John Wiley \& Sons, New York, NY, USA, 2001.

[14] K. C. Gupta, R. Garg, I. Bahl, and P. Bhartia, Microstrip Lines and Slotline, Artech-House, Boston, Mass, USA, 2nd edition.

[15] Matlab, 2008, http://www.mathworks.com/.

[16] Zeland IE3D EM simulator v. 11, http://www.mentor.com/.

[17] Ansoft HFSS v. 12, http://www.ansoft.com/.

[18] D. M. Pozar, Microwave Engineering, John Wiley \& Sons, New York, NY, USA, 2nd edition, 1998.

[19] B. C. Wadell, Transmission Line Design Handbook, Artech House. 

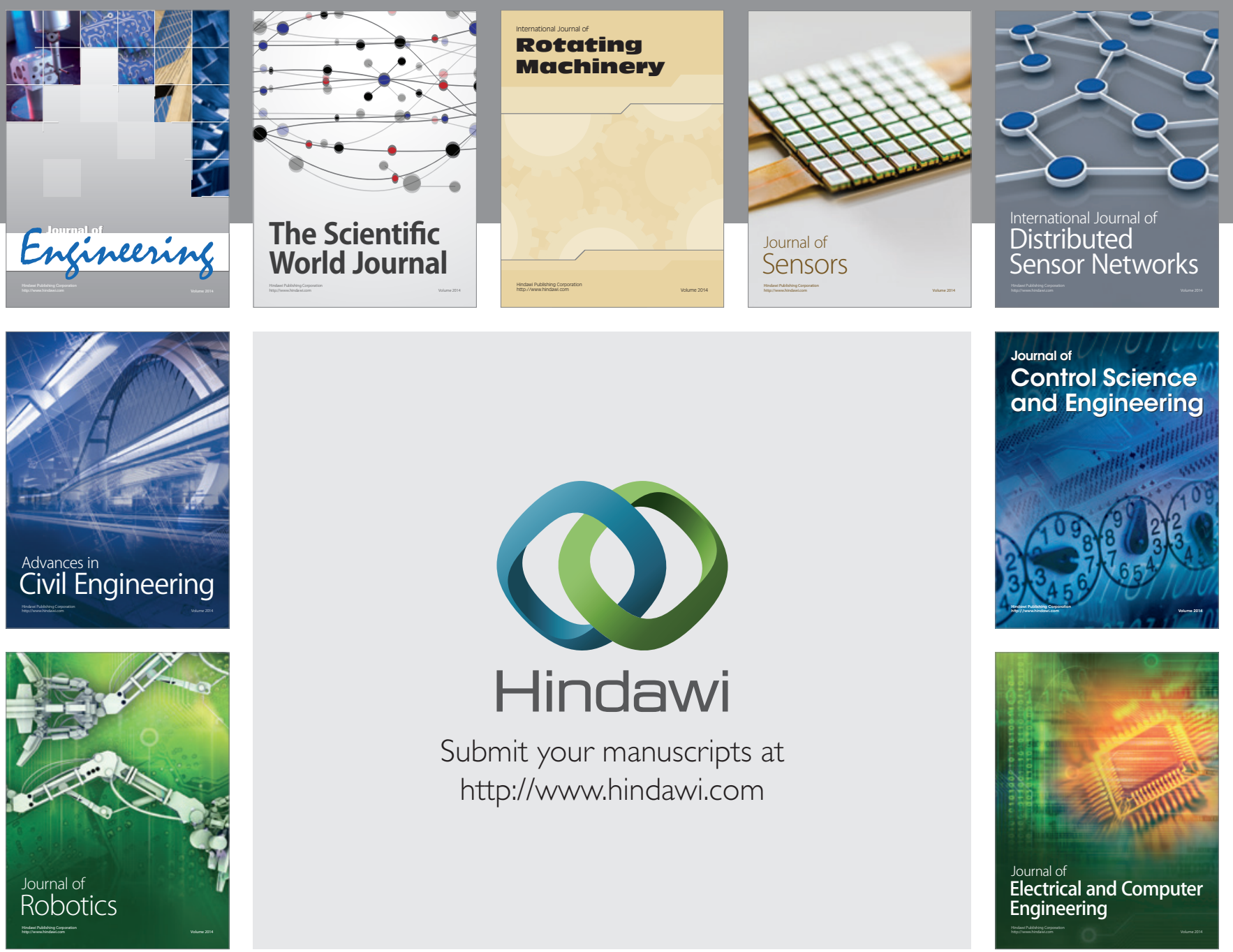

Submit your manuscripts at

http://www.hindawi.com
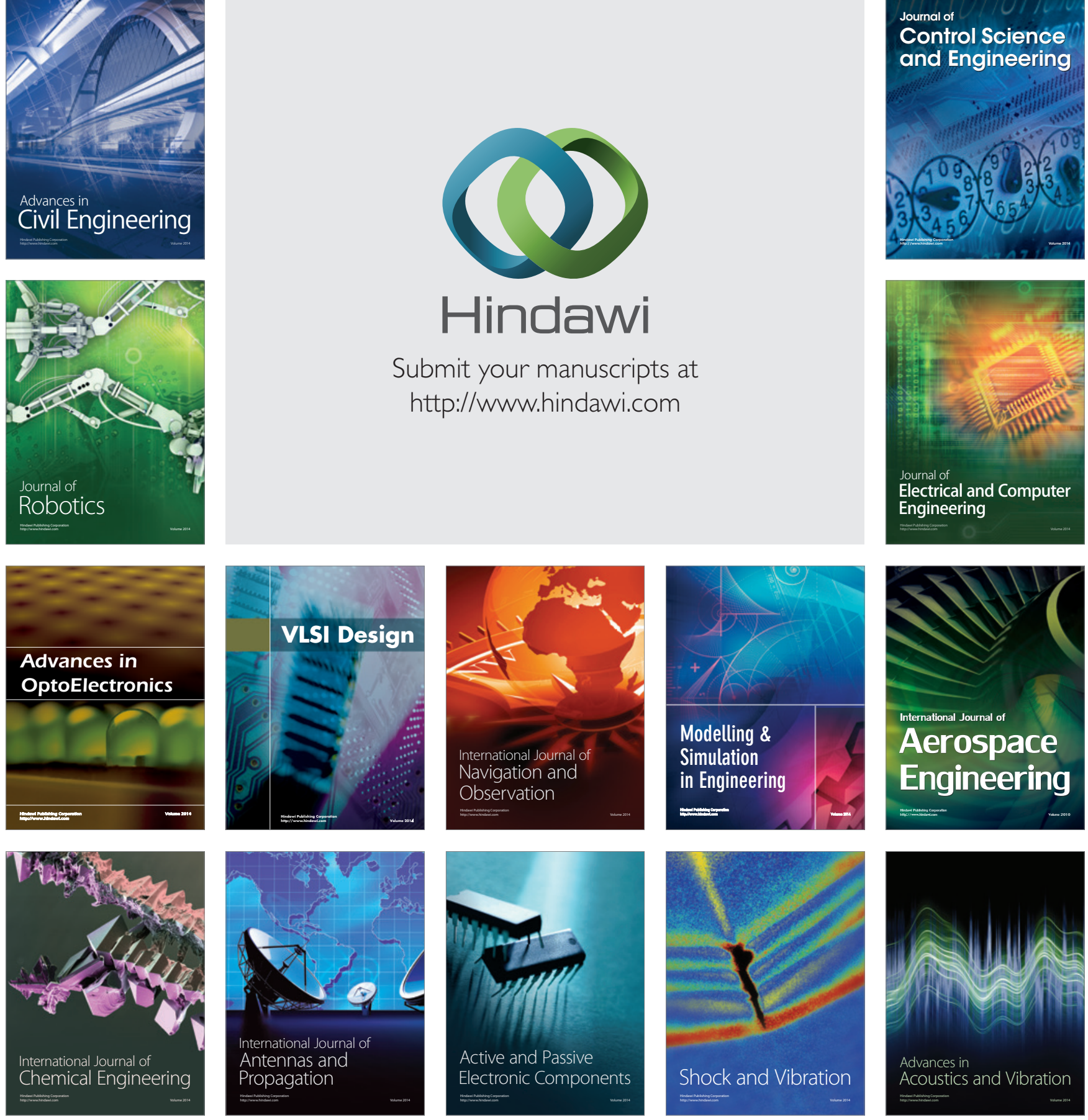